\title{
Preferensi Stakeholder dalam Pengembangan Ekowisata Mangrove Gunung Anyar Surabaya
}

\author{
Hera Windy Wahyono dan Dian Rahmawati \\ Departemen Perencanaan Wilayah dan Kota, Fakultas Teknik Sipil dan Perencanaan \\ Institut Teknologi Sepuluh Nopember (ITS) \\ e-mail :dnrahmawati66@gmail.com
}

\begin{abstract}
Abstrak-Ekowisata mangrove Gunung Anyar berpotensi untuk dikembangkan. Ekowisata mangrove Gunung Anyar sendiri keindahan alam yang berbeda dibandingkan dengan ekowisataekowisata yang ada di Kota Surabaya. namun tidak diimbangi dengan pengembangan kawasan ekowisata mangrove yang optimal. Permasalahan tersebut menyebabkan kurangnya jumlah kunjungan wisatawan, kurang beragamnya atraksi wisata. Berdasarkan permasalahan tersebut maka dirumuskan pertanyaan penelitian ini yaitu Sehingga dapat merumuskan rekomendasi pengembangan ekowisata mangrove Gunung Anyar Kelurahan Gunung Anyar Tambak berdasarkan preferensi Stakeholder. Berdasarkan hasil analisis didapatkan bahwa, sasaran pertama Meningkatkan pengetahuan tentang kegiatan perlindungan ekowisata mangrove Gunung Anyar Surabaya, meningkatkan pemahaman akan lingkungan alam sekitar mangrove dan karakteristik ekowisata dan karakteristik ekowisata, peran serta masyarkat,dan memberikan fungsi koordinasi oleh pemerintah maupun swasta. Sasaran kedua, ditemukan 7 Faktor pengembangan ekowisata mangrove berdasarkan preferensi Stakeholder. Dan Ketiga, menyusun konsep wisata berbasis ecotourism, mengadakan pelatihan edukasi tentang ekowisata mangrove, pengembangan fasilitas dan pelayanan wisata, peningkatan modal usaha wisata, meningkatkan koordinasi antara masyarakat sekitar dengan stakeholder, melakukan promosi, Meningkatkan aksesibilitas kawasan ekowisata mangrove Gunung Anyar Surabaya
\end{abstract}

Kata Kunci-Pengembangan Wisata, Wisata Alam, Prefensi Stakeholder.

\section{PENDAHULUAN}

$\mathrm{P}$ ARIWISATA merupakan salah satu faktor penting dalam perkembangan perekonomian Indonesia. Hal ini karena pariwisata merupakan ujung tombak dari kemajuan perekonomian suatu negara. Tujuan pengembangan pariwisata akan berhasil dengan optimal bila ditunjang oleh potensi daerah yang berupa objek wisata baik wisata alam maupun wisata buatan manusia. Pembangunan dan pengembangan daerah menjadi daerah tujuan wisata tergantung dari daya tarik wisata itu sendiri yang dapat berupa keindahan alam, tempat bersejarah, tata cara hidup bermasyarakat maupun upacara keagamaan. [1]

Kota Surabaya merupakan salah satu kota di Jawa Timur dikenal memiliki kawasan wisata pantai yang edukatif yang banyak dan menjadi daya tarik wisata yang beraneka ragam dan tidak sama dengan pantai satu dengan pantai yang lainnya. Salah satu Kawasan Pantai yang edukatif dan menarik untuk dikunjungi yakni Ekowisata Mangrove Gunung Anyar yang terletak di Kelurahan Gunung Anyar, Kecamatan Gunung Anyar, Kota Surabaya. [2].

Selain itu potensi yang lainnya yakni ekowisata mangrove Gunung Anyar dilalui oleh Jalur dan akses Tol Tambak Sumur jalan menuju kawasan wisata sudah menggunakan jalan aspal sehingga memudahkan wisatawan yang berkunjung. Namun, masih terdapat masalah dalam pengembangan kawasan ekowisata angrove Gunung Anyar, berupa lahan daerah sekitar pesisr yang masih milik perseorangan dari mulai warga Kelurahan Gunung Anyar Tambak, swasta, dan pemerintah sehingga kurang terlibat dalam mendukung pengembangan kawasan ini dan tidak dapat secara optimal mengembangkan kawasan wisata ekowisata mangrove Gunung Anyar [3]

Permasalahan yang lain yakni kurang beragamnya atraksi wisata sehingga menyebabkan kurangnya jumlah kunjungan wisatawan. Semakin bagus atraksi wisata, semakin banyak pula permintaan untuk mengunjungi kawasan wisata tersebut dan semakin berkembang pula atraksi wisata tersebut. Berdasarkan permasalahan tersebut diatas maka diperlukan penelitian untuk mengembangkan kawasan ekowisata mangrove Gunung Anyar berdasarkan preferensi Stakeholder. [4]

Preferensi Stakeholder adalah keikut sertaan ketiga Stakeholder (pemerintah, swasta, dan masyarakat) dalam memecahkan permasalahan yang ada di ekowisata mangrove Gunung Anyar. Dalam hal ini, ketiga Stakeholder (pemerintah, swasta, dan masyarakat) yang aktif memikirkan, merencanakan, melaksanakan dan mengevaluasi programprogram demi pengembangan ekowisata mangrove Gunung Anyar. Melalui penelitian ini diharapkan dapat menjadi masukan bagi pelaku pembangunan untuk mengoptimalkan pengembangan kawasan ekowisata mangrove Gunung Anyar. [5]

\section{METODE PENELITIAN}

\section{A. Jenis dan Pendekatan Penelitian}

Pendekatan yang digunakan dalam penelitian ini adalah pendekatan rasionalistik [6] . Jenis penelitian dalam penelitian ini adalah deskriptif kualitatif.

\section{B. Variabel Penelitian}

1. Variabel komponen ekowisata mangrove Gunung Anyar yang digunakan dalam penelitian ini, antara lain :

- Kegiatan Perlindungan sumber daya alam

- Upaya kesadaran masyarakat

- Manfaat peluang usaha 
- Pengelolah kawasan ekowisata

2. Variabel Faktor pengembangan ekowisata mangrove berdasarkan preferensiStakeholder yang digunakan dalam penelitian ini, antara lain:

- Jenis wisata alam yang terdapat di Ekowisata Manggrove

- Jenis atraksi kegiatan yang terdapat pada kawasan

- Ketersedian toko/souvenir

- Ketersediaan warung/ depot

- Ketersediaan tempat parkir

- Ketersediaan MCK

- Ketersediaan fasilitas peribadatan

- Ketersediaan fasilitas keamanan umum

- Ketersediaan pusat informasi

- Ketersediaan moda angkutan umum menuju objek wisata

- Kondisi jalan menuju objek wisata

\section{Populasi dan Sampel}

Responden penelitian ini ditentukan dengan metode purposive sampling. Dalam penelitian ini yang menjadi populasi adalah keseluruhan stakeholder yang berkaitan dengan pengembangan pariwisata di ekowisata Gunung Anyar Surabaya. Jumlah responden yang dibutuhkan dalam menentukan faktor-faktor pengembangan ekowisata mangrove berdasarkan preferensi stakeholder responden yang dibutuhkan sebanyak 5 orang dengan penentuan kriteria:

1. Termasuk kedalam pengelola kawasan wisata Pantai Pidakan

2. Mengikuti perkumpulan karang taruna di kawasan wisata Pantai Pidakan

3. Memahami kawasan wisata Pantai Pidakan sebagai kawasan wisata pantai

4. Terlibat langsung dalam pengelolaan Obyek Wisata Pantai Pidakan

\section{Teknik Pengumpulan Data}

Teknik yang dilakukan dalam penelitian ini sebagai berikut:

1. Wawancara

Wawancara dilakukan untuk mengetahui faktor-faktor yang mempengaruhi pengembangan ekowisata mangrove Gunung Anyar Surabaya berdasarkan preferensi stakeholder.

2. Observasi Lapangan

Observasi yang dilakukan untuk mengetahui dilakukan antara lain konservasi, edukasi, ekonomi, peran aktif masyarakat, atraksi wisata, prasarana dan sarana, transportasi/ aksesibilitas, fasilitas pendukung pada ekowisata mangrove Gunung Anyar Surabaya.

\section{HASIL DAN PEMBAHASAN}

Hasil dan pembahasan dalam penelitian ini dijelaskan menurut sasaran penelitian, yaitu sebagai berikut :

\section{A. Analisis Identifikasi Komponen Ekowisata Mangrove}

\section{Gunung Anyar}

Dari hasil analisa diatas dapat diperoleh beberapa Identifikasi komponen ekowisata mangrove Gunung Anyar Surabaya. yaitu sebagai berikut :

1. Meningkatkan pengetahuan tentang kegiatan perlindungan mangrove dan membudidayakan penanaman bibit mangrove bertujuan melestarikan tumbuhan hayati.

2. Meningkatkan pemahaman akan lingkungan alam sekitar mangrove dan karakteristik Ekowisata yang terkait pemaham mangrove Gunung Anyar masyarkat sekitar yang andil dalam pengelolahan dan perkembangan wisata mangrove. Seperti merawat dan menanam bibit mangrove. perlindungan alam dan wawasan mengenai ekowisata

3. Peran serta masyarkat dapat terwujud karena manfaat lapangan perkerjaan dan usaha jasa wisata yang secara tidak langsung dapat meningkatkan pendapatan masyarkat sekitar yang andil dalam pengelolahan dan perkembangan wisata

4. Memberikan fungsi koordinasi terhadap pengelola untuk ada campur tangan oleh pemerintah maupun swasta. Dalam perkembangan wisata mangrove. Seperti merawat dan menanam bibit mangrove Gunung Anyar

B. Faktor pengembangan ekowisata mangrove berdasarkan preferensi Stakeholder

Tabel 1.

Faktor pengembangan ekowisata mangrove berdasarkan preferensi

\begin{tabular}{|c|c|c|}
\hline No. & $\begin{array}{c}\text { Faktor } \\
\text { Pengembangan }\end{array}$ & Kesimpulan \\
\hline 1. & $\begin{array}{l}\text { Pemandangan } \\
\text { alam, dan jenis } \\
\text { objek wisata aam } \\
\text { yang menjadi } \\
\text { daya tarik wisata }\end{array}$ & 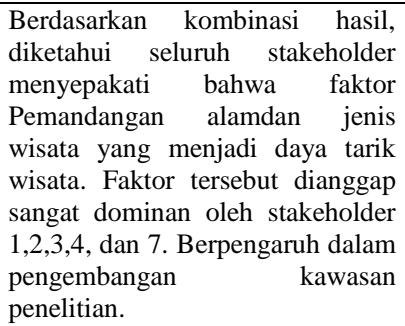 \\
\hline 2. & $\begin{array}{l}\text { Jenis atraksi yang } \\
\text { tidak merusak } \\
\text { lingkungan } \\
\text { mangrove }\end{array}$ & $\begin{array}{l}\text { Berdasarkan kombinasi hasil, } \\
\text { diketahui seluruh stakeholder } \\
\text { menyepakati bahwa faktor Jenis } \\
\text { atraksi kegiatan outbond/ camping, } \\
\text { jongging trak, wisata perahu dan } \\
\text { event besar berpengaruh dalam } \\
\text { pengembangan kawasan } \\
\text { penelitian. Faktor tersebut } \\
\text { dianggap berpengaruh karena } \\
\text { berulang sebanyak 5 kali. } \\
\text { berpengaruh dalam pengembangan } \\
\text { kawasan penelitian. }\end{array}$ \\
\hline 3. & $\begin{array}{l}\text { Terdapat pusat } \\
\text { toko souvenir } \\
\text { yang menjual } \\
\text { cinderamata khas } \\
\text { ekowisata } \\
\text { mangrove }\end{array}$ & $\begin{array}{l}\text { Berdasarkan kombinasi hasil, } \\
\text { diketahui bahwa } 2,3 \text { dari } 6 \\
\text { stakeholder menyepakati bahwa } \\
\text { faktor Terdapat pusat toko } \\
\text { souvenir yang menjual } \\
\text { cinderamata khas berpengaruh } \\
\text { dalam pengembangan kawasan } \\
\text { penelitian. }\end{array}$ \\
\hline
\end{tabular}




\begin{tabular}{|c|c|c|}
\hline 4. & \begin{tabular}{l}
\multicolumn{2}{l}{ Ketersediaan } \\
sarana, tempat \\
parkir, musholla, \\
warung/ depot \\
yang mendukung \\
kawasan \\
ekowisata \\
Gunung anyar
\end{tabular} & $\begin{array}{l}\text { Berdasarkan kombinasi hasil, } \\
\text { diketahui seluruh stakeholder } \\
\text { menyepakati bahwa faktor } \\
\text { Ketersediaan sarana yakni warung, } \\
\text { tempat parkir, musholla, MCK } \\
\text { berpengaruh dalam pengembangan } \\
\text { kawasan penelitian. Faktor } \\
\text { tersebut dianggap sangat dominan } \\
\text { oleh stakeholder 1,2,3, 4, 5, 6, 7,8. } \\
\text { Namun harus di luar zona lindung } \\
\text { agar tidak merusak tumbuhan } \\
\text { mangrove berpengaruh dalam } \\
\text { pengembangan kawasan } \\
\text { penelitian. }\end{array}$ \\
\hline 5. & $\begin{array}{l}\text { Pengadaan } \\
\text { fasilitas keamanan } \\
\text { umum untuk } \\
\text { memantau } \\
\text { mangrove dan } \\
\text { wisatawan, } \\
\text { berupa pos untuk } \\
\text { keamanan } \\
\text { wisatawan }\end{array}$ & $\begin{array}{l}\text { Berdasarkan kombinasi hasil, } \\
\text { diketahui seluruh stakeholder } \\
\text { menyepakati bahwa faktor } \\
\text { Penyediaan fasilitas keamanan } \\
\text { umum berupa pos untuk keamanan } \\
\text { wisatawan berpengaruh dalam } \\
\text { pengembangan kawasan wisata } \\
\text { penelitian. Faktor tersebut } \\
\text { dianggap sangat dominan } \\
\text { stakeholder } 1,2,3,4,5,6,7,8 . \\
\text { Namun harus di luar zona lindung } \\
\text { agar tidak merusak tumbuhan } \\
\text { mangrove berpengaruh dalam } \\
\text { pengembangan } \\
\text { penelitian. }\end{array}$ \\
\hline 6. & $\begin{array}{lr}\text { Informasi } & \text { dan } \\
\text { Promosi berupa } \\
\text { papan penunjuk } \\
\text { jalan, brosur/ } \\
\text { katalog dan sosial } \\
\text { media } \\
\text { mengetahui } & \text { objek } \\
\text { dan daya tarik } \\
\text { wisata }\end{array}$ & $\begin{array}{l}\text { Berdasarkan kombinasi hasil, } \\
\text { diketahui seluruh stakeholder } \\
\text { menyepakati bahwa faktor } \\
\text { Ketersediaan pusat informasi } \\
\text { berupa galeri Pantai Pidakan } \\
\text { berpengaruh dalam pengembangan } \\
\text { kawasan wisata penelitian. Faktor } \\
\text { tersebut dianggap sangat dominan } \\
\text { oleh stakeholder 1, 2, 4, } 7 . \\
\text { Sehingga dapat dikatakan faktor } \\
\text { berpengaruh dalam pengembangan } \\
\text { kawasan penelitian. }\end{array}$ \\
\hline 7. & $\begin{array}{l}\text { Jaringan jalan } \\
\text { sehingga } \\
\text { memperlancar } \\
\text { sirkulasi jalan } \\
\text { menuju objek } \\
\text { wisata }\end{array}$ & $\begin{array}{l}\text { Berdasarkan kombinasi hasil, } \\
\text { diketahui seluruh stakeholder } \\
\text { menyepakati bahwa faktor } \\
\text { Ketersediaan peningkatan jaringan } \\
\text { jalan berpengaruh dalam } \\
\text { pengembangan kawasan wisata } \\
\text { penelitian berpengaruh dalam } \\
\text { pengembangan kawasan wisata } \\
\text { penelitian. Faktor tersebut } \\
\text { dianggap sangat dominan oleh } \\
\text { sangat dominan stakeholder 1,2,3, } \\
\text { 4, } 5,6,7,8 \text {. Namun harus di luar } \\
\text { zona lindung agar tidak merusak } \\
\text { tumbuhan mangrove berpengaruh } \\
\text { dalam pengembangan kawasan } \\
\text { penelitian. }\end{array}$ \\
\hline
\end{tabular}

C. Rekomendasi pengembangan ekowisata mangrove berdasarkan prefensi Stakeholder

Berikut akan dijelaskan rekomendasi pengembangan pada ekowisata mangrove berdasarkan preferensi Stakeholder.

1. Menyusun konsep wisata berbasis ecotourism dan membentuk atraksi daya tarik wisata baru yang dapat menarik minat wisatawan. yakni masyarakat sekitar ikut berpartisipasi dalam partisipasi keterampilan dalam kebudayaan maupun mengolah cinderamata khas ekowisata mangrove Gunung Anyar Surabaya

2. Mengadakan pelatihan edukasi tentang ekowisata mangrove dan pendampingan kepada masyarakat ekowisata mangrove Gunung Anyar Surabaya sekitar selaku yang berperan penuh dalam pengembangan wisata.

3. Pengembangan fasilitas dan pelayanan wisata yang mendukung seperti tempat parkir, musholla, MCK, warung, pos keaman , pusat informasi, dan toko souvenir kawasan ekowisata mangrove Gunung Anyar Surabaya

4. Peningkatan modal usaha wisata melalui dukungan ekternal pemerintah, swasta dengan pengajuan proposal dana.

5. Meningkatkan koordinasi antara masyarakat sekitar dengan stakeholder yang dimulai dengan perencanaan, sosialisasi, pelaksanaan dan pemantauan konsep pengembangan ekowisata mangrove

6. Melakukan promosi melalui media cetak maupun media elektronik untuk mendapatkan dukungan dan partisipasi masyarakat mangrove Gunung Anyar maupun masyarakat Surabaya

7. Meningkatkan aksesibilitas menuju kawasan wisata ekowisata dengan perbaikan jalan lingkungan yang menjadi akses utama kegiatan pariwisata di kawasan wisata kawasan ekowisata mangrove Gunung Anyar Surabaya

\section{KESIMPULAN}

Berdasarkan analisis-analisis yang telah dilaksanakan, terdapat komponen ekowisata mangrove Gunung anyar ada (4) komponen untuk seperti konservasi, pendidikan, ekonomi, dan peran aktif masyarakat. Menjadi 7 Faktor pengembangan ekowisata mangrove berdasarkan preferensi stakeholder. Dan rekomendasi pengembangan pada ekowisata mangrove berdasarkan preferensi stakeholder, seperti menyusun konsep berbasis ecotourism, pelatihan tentang mangrove, fasilitas dan pelayanan ekowisata, peningkatkan modal usaha, koordasi antara Pemerintah dan swasta dan meningkatkan aksebilitas.

\section{DAFTAR PUSTAKA}

[1] Yoeti, "Yoeti." 1985.

[2] Thomi, "Kondisi Mangrove di Surabaya." 2015.

[3] D. Rahmawati, "Konsep Land Sharing Sebagai Alternatif Penataan Pemukuman Nelayan di Kelurahan Gunung Anyar Tambak Surabaya," 2015

[4] H. Adiwijaya, "Kondisi Mangrove Pantai Timur Surabaya Dan Dampaknya Terhadap Lingkungan Hidup," 2015.

[5] I. K. Suwena, Format Pariwisata Masa Depan" dalam Pariwisata Berkelanjutan dalam Pusaran Krisis Global. Denpasar: Udayana University Press, 2010.

[6] I. M. Nugrahanti, "Pengembangan Permukiman Nelayan Berbasis Ekowisata Di Pantai Timur Surabaya," 2012. 